\title{
Screening and application of microbial inoculants for sludge composting in expressway service area of northwest China
}

\author{
Jing Zhao ${ }^{1}$, Xiao wei Wang ${ }^{2,3}$, Hua Fan ${ }^{2,3,}$, Chun ping Fan ${ }^{2,3}$, She gang Shao ${ }^{1}$, and Jian bo Xie ${ }^{4}$ \\ ${ }^{1}$ Key Laboratory of Traffic Industry of Highway Traffic Environmental Protection Technology, Beijing, 100032, China \\ ${ }^{2}$ Beijing Environmental Engineering Technology Co., Ltd., Beijing 100101, China \\ ${ }^{3}$ Beijing Engineering Technology Research Center for Comprehensive Treatment and Recycling of Urban Solid Waste, Beijing 100101; \\ ${ }^{4}$ Shuangzhi Environment and Development Technology Co., Ltd., Beijing 102200, China
}

\begin{abstract}
Taking sludge in northwest China's expressway service area as the research object, four dominant strains, including Bordetella sp. M05, Ochrobactrum sp. M06, Bacillus subtilis M07 and Staphylococcus sciuri M09, were obtained through specific screening. These microbes were prepared into inoculants and effectively promoted sludge composting. The time for the fermentation temperature of the composting process to reach $50^{\circ} \mathrm{C}$ was 3 days earlier than that of the control group. The high temperature $\left(>50^{\circ} \mathrm{C}\right)$ lasted for 12 days and the highest temperature reached $63.5^{\circ} \mathrm{C}$. After composting, the product was dark in color, free from odor, and the contents of organic matter, nitrogen, phosphorus and potassium increased by $44.1 \%, 125.9 \%$, $311.1 \%$ and $269.2 \%$, respectively, which made the composted product meet standards of GB/T 23486-2009 Sludge for Landscaping.
\end{abstract}

\section{Introduction}

In China, the expressway service area is an area set up to cater needs of drivers and passengers who are far away from the city for catering, accommodation, maintenance and refueling. This area generally consists of a comprehensive service building, toilet, parking lot, maintenance station, sewage treatment room and other facilities. The sewage from toilets in the service area will be discharged into the septic tank for treatment, and the generated sludge or manure needs to be transported outward. In northwest China, generally, service areas are far away from urban and rural areas, and the cost of transporting sludge and manure to the outside of the service area is high. Moreover, outdoor stacking will produce odor and cause environmental pollution problems, and harmful substances will penetrate into the ground along with seepage, polluting soil and groundwater. Therefore, in the expressway service area in northwest China, besides sewage, it is necessary to further treat sludge and manure generated from sewage treatment. Kitchen waste and garden waste in the service area can also be treated together with sludge and manure.

Aerobic composting is a composting method for the harmless and resource treatment of solid organic matters. Its mechanism is to turn corruptible organics into stable humus through the synergistic action of bacteria, fungi, actinomycetes and other microorganisms in aerobic conditions[1]. The composting method can not only effectively treat organic solid waste, but also produce suitable humus which can be used as the substrate of organic fertilizer. Aerobic composting can deliver the effective utilization of waste, and has the advantages of less investment and low operating cost.

At present, there have been many researches on composting process, mechanism and products, but different sources and conditions of composting raw materials will bring different composting characteristics, while there are few researches on on-site treatment of sludge produced in expressway service areas in northwest China. Composting is an aerobic process, in which microbes play an important role. Microbes can decompose organic matters into stable substances, thus improving soil quality and fertility[2]. Therefore, in this paper, the composting sludge of expressway was studied and microbial inoculants were screened, microbial inoculants were prepared after expanding cultivation and applied to sludge composting, which provides technical support for the comprehensive treatment of organic solid waste in special environment.

\section{Materials and methods}

\subsection{Test materials}

The test sludge came from the domestic garbage and sewage treatment system in a high-speed service area in northwest China, manure came from septic tank for toilets, kitchen waste was food residue, and garden waste was dead branches and leaves after cleaning during operation.

* Corresponding author: fanhua@besgrd.com 


\subsection{Strain screening and culture}

The types of screening media were as follows:

LB liquid medium: yeast powder $5 \mathrm{~g} / \mathrm{L}$, tryptone 10 $\mathrm{g} / \mathrm{L}, \mathrm{NaCl} 5 \mathrm{~g} / \mathrm{L}$, deionized water $1 \mathrm{~L}$, sterilized at $121^{\circ} \mathrm{C}$ for $20 \mathrm{~min}$.

Protein liquid medium: skim milk powder $50 \mathrm{~g} / \mathrm{L}$, soluble starch $10 \mathrm{~g} / \mathrm{L}, \mathrm{K}_{2} \mathrm{HPO}_{4} 1 \mathrm{~g} / \mathrm{L}, \mathrm{MgSO}_{4} 0.2 \mathrm{~g} / \mathrm{L}$, deionized water $1 \mathrm{~L}$, sterilized at $121^{\circ} \mathrm{C}$ for $20 \mathrm{~min}$.

LB solid agar medium: yeast powder $5 \mathrm{~g} / \mathrm{L}$, tryptone $10 \mathrm{~g} / \mathrm{L}, \mathrm{NaCl} 5 \mathrm{~g} / \mathrm{L}$, agar powder $18-20 \mathrm{~g} / \mathrm{L}$, deionized water $1 \mathrm{~L}$, sterilized at $121^{\circ} \mathrm{C}$ for $20 \mathrm{~min}$, and poured into a flat plate for solidification.

Protein solid agar medium: skim milk powder $50 \mathrm{~g} / \mathrm{L}$, soluble starch $10 \mathrm{~g} / \mathrm{L}, \mathrm{K}_{2} \mathrm{HPO}_{4} 1 \mathrm{~g} / \mathrm{L}, \mathrm{MgSO}_{4} 0.2 \mathrm{~g} / \mathrm{L}$, agar powder $18-20 \mathrm{~g} / \mathrm{L}$, deionized water $1 \mathrm{~L}$, sterilized at $121^{\circ} \mathrm{C}$ for $20 \mathrm{~min}$ and poured into a plate to solidify after the temperature drops below $60^{\circ} \mathrm{C}$ for later use.

PDA solid agar medium: potato starch agar $1.5 \%$ $(\mathrm{w} / \mathrm{w})$, glucose $1.5 \%(\mathrm{w} / \mathrm{w})$, sterilized at $121^{\circ} \mathrm{C}$ for $20 \mathrm{~min}$, and poured into a flat plate for solidification.

$5 \mathrm{~g}$ of the composted product was placed in a $500 \mathrm{~mL}$ triangular flask, add $50 \mathrm{~mL}$ of deionized water, shaken and leached for $2 \mathrm{~h}$ at $120 \mathrm{rpm}$. Take the extraction liquid at the top to carry out gradient dilution to $10^{-2}, 10^{-3}, 10^{-4}$ and $10^{-5}$, take $200 \mu \mathrm{L}$ of the extract liquid to coat it on a flat plate with a screened medium which was cultured in a constant temperature incubator at $28^{\circ} \mathrm{C}$ for $24-48 \mathrm{~h}$, select a single colony for streak cultivation and carry out strain detection.

\subsection{Preparation and application of microbial inoculants}

The fermentation medium was used to expand the cultivation of screened strains for preparing microbial inoculants.

The fermentation medium: corn flour $30 \mathrm{~g} / \mathrm{L}$, molasses $5 \mathrm{~g} / \mathrm{L}$, corn steep liquor $10 \mathrm{~g} / \mathrm{L}$, peptone $5 \mathrm{~g} / \mathrm{L}$, beef extract $1 \mathrm{~g} / \mathrm{L}, \mathrm{KH}_{2} \mathrm{PO}_{4} 2 \mathrm{~g} / \mathrm{l}, \mathrm{MgSO}_{4} 0.1 \mathrm{~g} / \mathrm{l}, \mathrm{MnSO}_{4} 0.1 \mathrm{~g} / \mathrm{l}$ and $\mathrm{CaCO}_{3} 5 \mathrm{~g} / \mathrm{L}$, sterilized at $115^{\circ} \mathrm{C}$ for 30 min with a pH of 7.0. After fermentation for $28 \mathrm{~h}$, mix fermentation broth with wheat bran at a ratio of $1: 1.5(\mathrm{~V}: \mathrm{W})$, and then dried at room temperature to be used as microbial inoculants later.

\subsection{Composting fermentation}

The prepared microbial inoculant was added to compost to promote the degradation of organic matters. Sludge (containing a small amount of kitchen waste which accounts for about $15 \%$ by mass), garden waste and microbial inoculant were added to a high-speed mixer according to the mass ratio of 10: 5: 1 for mixing, and the water content was adjusted to $50 \%$ to $55 \%$, thus obtaining the raw materials for sludge composting. Raw materials were stacked according to the length, width and height of $5 \mathrm{~m}, 2 \mathrm{~m}$ and $1.5 \mathrm{~m}$ respectively to carry out windrowing static aeration in aerobic conditions, as shown in Fig. 1. The temperature of the compost was measured once every morning and afternoon for 4 weeks continuously, and changes of temperature and maturity before and after composting were observed.

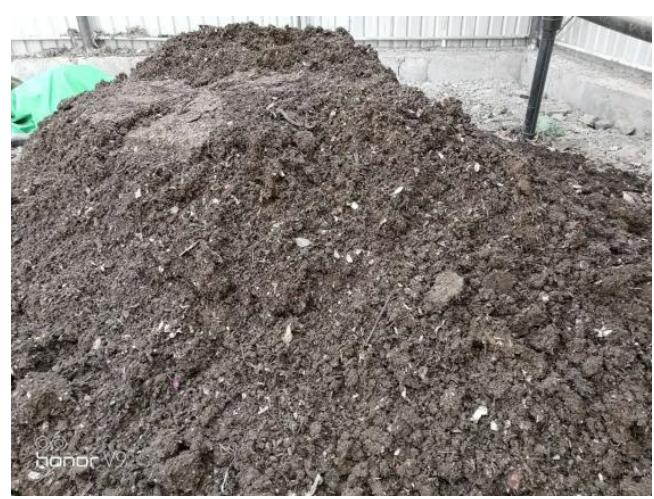

(a)

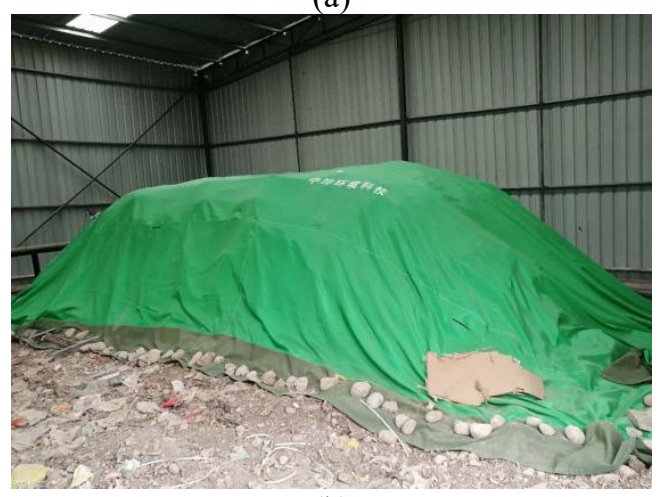

(b)

Fig. 1. Mixed composting materials and composting test. (a): mixed materials; (b): composting test.

\section{Results and analysis}

\subsection{Screening of strains}

\subsubsection{Strain identification}

After specific screening, four dominant strains were obtained, which were identified as Bordetella sp. M05,

Ochrobactrum sp. M06, Bacillus subtilis M07 and Staphylococcus sciuri M09 through sequencing analysis of $16 \mathrm{~s}$ rRNA. Four dominant strains grew rapidly on protein solid agar medium, and they were fermented with fermentation medium to prepare microbial inoculant. The inoculation amount of each strain is $5 \%$, and the growth curve of inoculated strains in the fermentor is shown in Fig. 2. After fermentation for 20 hours the OD value reached its highest value, and then gradually tended to be flat, so the best fermentation time was $24 \mathrm{~h}$. 


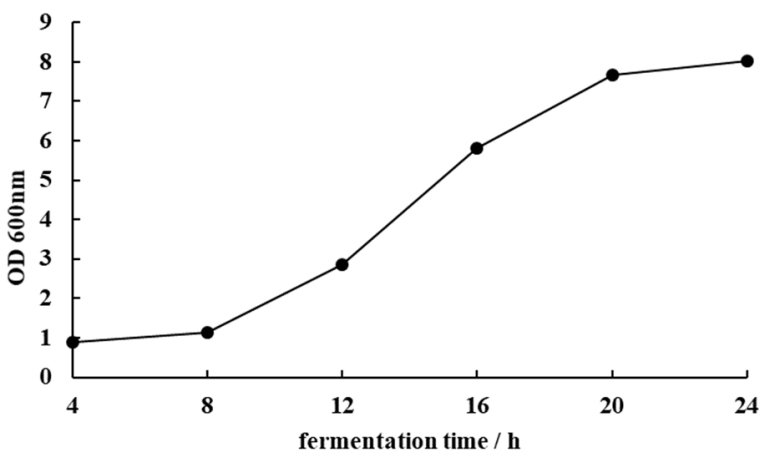

Fig. 2. Growth curve of main strains in fermentor.

\subsubsection{High-throughput aequencing}

Samples of the sludge for composting were taken, and species of microbial flora in the composting process were analyzed by high-throughput sequencing of the conserved sequence, $16 \mathrm{~S}$ rRNA. Results of preliminary analysis showed that microbes in sludge for composting mainly including Firmicutes, Thermotogae, Bacteroidetes, and Thermotogae, and the relative abundance were $26.8 \%$, 10.69\%, 4.04\% and 58.47\%, respectively. Firmicutes contained a small amount of Euryarchaeota which usually contain methanogens, halobacillus which can live in extremely high salinity, and some thermophilic aerobic and anaerobic bacteria[3].

\subsubsection{Fermentation and microbial inoculant preparation}

After fermentation, the fermentation broth was mixed with wheat bran at a ratio of $1: 1.5(\mathrm{~V}: \mathrm{W})$, and then evenly stirred and dried at room temperature to obtain the microbial inoculant of Bordetella sp. M05. Three days after the start of composting, the microbial inoculant was added into the compost, stirred and continuously fermented.

\subsection{Aerobic composting test}

\subsubsection{Temperature changes during composting}

With the same mixed materials (sludge, kitchen waste and garden waste) as the research object, the compost without microbial inoculant as the blank control group, and the compost added with microbial inoculant as the test group, the oxygen content in the two piles was automatically controlled to be above $12 \%$ by static aeration, and the temperature changes of the two compost were recorded, as shown in Fig. 3.

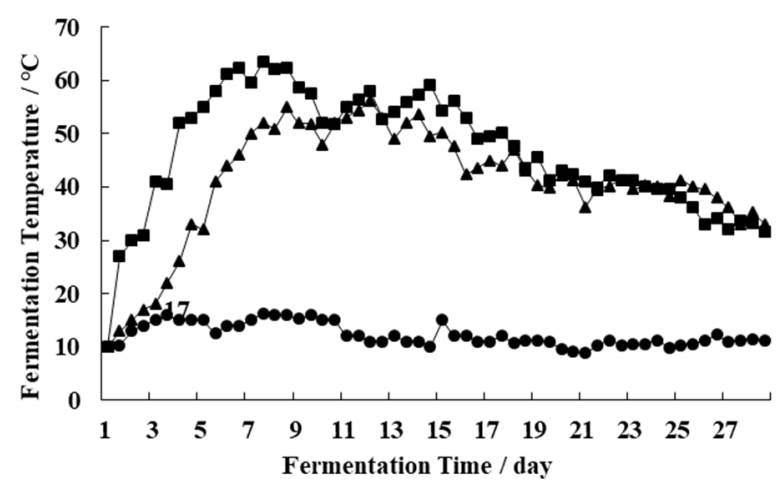

Fig. 3. Temperature History of Sludge for Composting. Mean of three temperature are shown. Dots: ambient temperature; square: test group; triangle: control group.

It can be seen from Fig. 3 that the temperature of the compost changes in a wave shape during the whole process. On the one hand, it is due to the poor mobility of microbial flora in solid fermentation, and when the nutrients around the microorganisms are gradually decomposed and reduced to a certain extent, the microbial activity is reduced; on the other hand, some odorous compounds (fatty acids, amines, aromatic hydrocarbons, sulfides, etc.) released during composting can inhibit the microbial growth to a certain degree[4].

On the whole, the temperature of the test group was higher than that of the control group. The temperature of the test group added with new microbial inoculant reached $50^{\circ} \mathrm{C}$ on the day 4 and levelled up to its highest value, namely $63.5^{\circ} \mathrm{C}$, on day 8 , and the temperature of test group was kept at $50^{\circ} \mathrm{C}$ for 12 days. However, the temperature of the control group reached $50^{\circ} \mathrm{C}$ on the day 7 , and levelled up to its highest value of $56.1^{\circ} \mathrm{C}$ on the day 12 , while the temperature of test group was kept at $50^{\circ} \mathrm{C}$ for 6 days.

\subsubsection{Technical index of composting}

Changes of the control group and test group before and after composting were shown in Table 1.

Table 1 Maturity ilndex of sludge for composting

\begin{tabular}{|c|c|c|c|c|}
\hline \multirow{2}{*}{ Item Index } & \multirow{2}{*}{$\begin{array}{c}\text { Before } \\
\text { Composting }\end{array}$} & \multicolumn{2}{|c|}{ After Composting } & \multirow{2}{*}{$\begin{array}{c}\text { GB/T 23486-2009 Sludge for } \\
\text { Landscaping }\end{array}$} \\
\hline & & Control Group & Test Group & \\
\hline Organic Matter/\% (drying basis) & 38.3 & 42.3 & 55.2 & $\geq 45 \%$ \\
\hline $\begin{array}{l}\text { Nitrogen } / \% \text { (in terms of total } \\
\text { nitrogen, drying basis) }\end{array}$ & 0.54 & 0.92 & 1.76 & \multirow{2}{*}{$\begin{array}{l}\text { Total nitrogen, phosphorus and } \\
\text { potassium content } \geqslant 3 \%\end{array}$} \\
\hline $\begin{array}{c}\text { Phosphorus } / \% \text { (calculated as } \\
\text { phosphorus pentoxide, drying } \\
\text { basis) }\end{array}$ & 0.63 & 1.84 & 2.59 & \\
\hline
\end{tabular}




\begin{tabular}{|c|c|c|c|c|}
\hline $\begin{array}{c}\text { Potassium/\% (calculated as } \\
\text { potassium oxide, drying basis) }\end{array}$ & 0.26 & 0.63 & 0.96 & \\
\hline $\mathrm{pH}$ & 6.22 & 7.33 & 7.15 & $\begin{array}{c}\text { Acidic soil with a pH of } 6.5- \\
8.5, \text { neutral and alkaline soil } \\
\text { with a pH of } 5.5-7.8\end{array}$ \\
\hline Moisture Content/\% & 56.3 & 41.2 & 37.3 & $\leq 40$ \\
\hline
\end{tabular}

Before and after composting, the contents of organic matter, nitrogen, phosphorus and potassium in the control group increased by $10.4 \%, 70.4 \%, 192.1$ and $142.3 \%$ respectively, while those in the test group increased by $44.1 \%, 125.9 \%, 311.1$ and $269.2 \%$ respectively. Therefore, the added microbial inoculant significantly improved the bioavailability of organic matter, nitrogen, phosphorus and potassium. Meanwhile, the higher composting temperature of the test group led to a lower final moisture content, which made it fully meet the requirements of GB/T 23486-2009 Sludge for Landscaping.

\subsubsection{Color and odor before and after composting}

The color of decomposed sludge in the test group was obviously deepened, showing a dark brown color, indicating that the decomposition was sufficient; and there was no volatilization of ammonia gas, so that odor substances were hardly produced. This might be due to the addition of microbial inoculants, which significantly increased the types and quantity of microbes in sludge for composting. It is speculated that most of these microbes are beneficial bacteria, which produce a large number of enzymes and organic acids while decomposing macromolecular organic matter in the sludge, which may stable the ammonia nitrogen to a certain degree[5].

However, the color of the control group hardly changed before and after composting, and ammonia volatilization still existed after 5 days. This might be due to the fact that the control group lack of dominant strains, and the ability to decompose organic matter in sludge was poor, resulting in insufficient stability of sludge.

\section{Conclusion}

Taking sludge in northwest China's expressway service area as the research object, four dominant strains, including Bordetella sp. M05, Ochrobactrum sp. M06, Bacillus subtilis M07 and Staphylococcus sciuri M09, were obtained through specific screening. These screened and optimized microbial inoculants showed a remarkable results when were applied in sludge composting, with the fermentation temperature of composting martials reaching $50^{\circ} \mathrm{C} 3$ days in advance, in which the highest temperature was $63.5^{\circ} \mathrm{C}$, and the temperature above $50^{\circ} \mathrm{C}$ was maintained for 12 days. The composted products were dark in color, free from odor, and the contents of organic matter, nitrogen, phosphorus and potassium increased by $44.1 \%, 125.9 \%, 311.1 \%$ and $269.2 \%$, respectively. The composted products meet the standards of GB/T 234862009 Sludge for Landscaping. However, when applied to composting activities in high-speed service areas, economic analysis shall be carried out according to local specific conditions, and considering the environmental temperature in northwest alpine regions, it is suggested to take thermal insulation measures for composting facilities.

\section{Acknowledgments}

This work was funded by the Key Laboratory of Highway Transportation Environmental Protection Technology Transportation Industry Open Project.

\section{References}

1. S. P. Gautam, P. S. Bundela, A. K.Pandey, M. K.Awasthi, S. Sarsaiya, Global J. Environ. Res 4: 43 (2010).

2. M. Rastogi, M. Nandal, B. Khosla, J. Exp. Biol. Ecol 6: e03343 (2020).

3. H. P. Horz, G. Conrads, Archaea, 1472-3646: 967271 (2010).

4. C. Li, H. Li, T. Yao, S. Gun, Bioresour. Technol 289: 121653 (2019).

5. J. D. Kim, J. S. Park, B. H. In, D. Kim, W. Namkoong, J. Hazard. Mater 154: 272 (2008). 